\title{
報 告 耳e.
}

\author{
COST 732 Workshop に参加して \\ COST 732 WORKSHOP on \\ "Quality Assurance of Micro-Scale Meteorological Models"
}

義江龍一郎*

Ryuichiro YOSHIE

2009 年 6 月 3 日から 6 月 5 日にかけて, ハンブルグ大学に おいて, COST 732 Workshop on "Quality Assurance of Micro Scale Meteorological Models”が開催された。COSTとは intergovernmental framework for European Cooperation in Science and Technology（科学技術におけるヨーロッパ協調のための政 府間レベルの枠組み) のことである。「何で $\mathrm{CO}$ と $\mathrm{S}$ と T を取 ってくるのか, 他にも取り方があるだろうに」と言いたくな る方も多いと思われるが，それはさておき鬼も角 COST には ヨーロッパの 36 力国(EU27 カ国+9 力国) もの国が加盟して いるのである。COST は加盟国の税金で運営されており事務 局はブリュッセルにある。研究費は拠出しないが，ヨーロッ パの科学者たちの研究協力のためのプラットフォーム（会議 費, 出版費, 旅費等) を提供している。COST には様々な分 野における数多くの研究プロジェクトがあるが, 各プロジェ クトはAction と呼ばれている。ひとつの Action の期間は 4 年 で，平均的にはひとつの Action につき年間 10 万ユーロのお 金が支払われているそうだ。COST 732 はそのうちのひとつで あり，都市の風通しや污染物質輸送を予測するための Micro-Scale Meteorological Models（主としてCFD）の品質を向 上させ保証することを目的としている。主査はハンブルグ大 学気象研究所の Michael Schatzmann 教授である。COST 732 の 活動は既に 4 年を経過しており, 今回の Workshop はその成果 を総括するものであった。Photo 1 に参加者の集合写真を示す が，ヨーロッパから約 50 名, アメリカから数名, 日本から 1 名（私）が参加した。私は日本建築学会の風環境数值計算 WGの活動を紹介してほしいと Schatzmann 教授から依頼され 参加したのである。

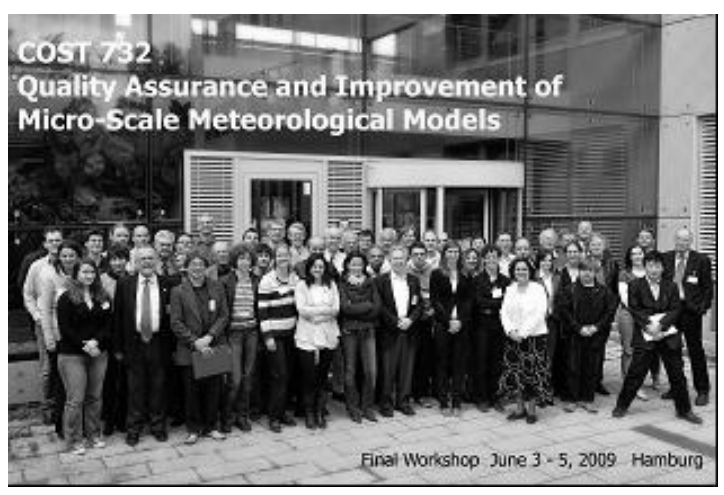

Photo 1 集合写真

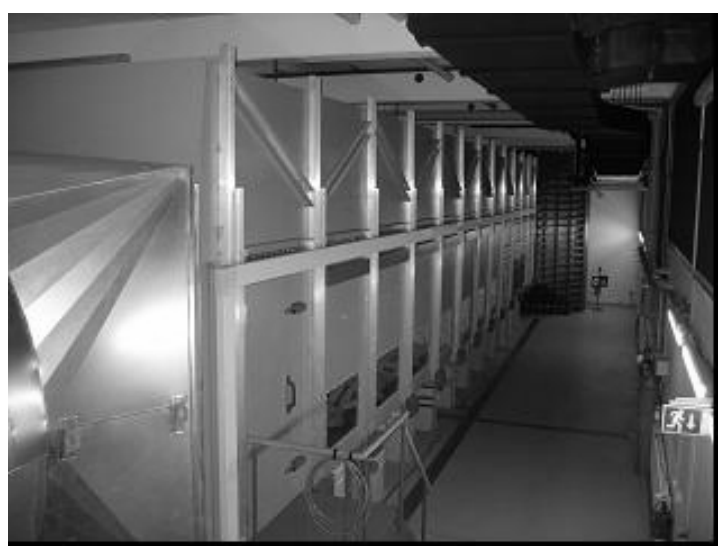

Photo 2 ハンブルグ大学の風洞

* 東京工芸大学工学部建築学科 教授

Professor, Department of Architecture, Tokyo Polytechnic University 
初日の 6 月 3 日の夜には, ハンブルグ大学の風洞実験施設

(Photo2, 3) において, チーズ\&ワインパーティーが行われ た。ここには幅 $4 \mathrm{~m} \times$ 高さ $3 \mathrm{~m}$ のテストセクションを持つ大型 風洞がある。同大学の Bernd Leitl 教授自ら設計し，材料を調 達し，職人を指揮して作ったそうである。パーティーの合間 にはレーザーライトシートとスモークを用いた流れの可視化 のデモンストレーションも行われた。風洞の中にはPhoto3に 示すように奇妙な形をした模型が並べられていた。これはヨ 一ロッパの典型的な都市形態をモデル化したものらしい。

2日目の6月 4 日の朝には, まずSchatzmann教授が COST 732 の背景と目的等の趣旨説明を行った。次に “Model Evaluation Activities Word Wide” と称したセッションが設けられていて, アメリカからの招待講演者 3 名と私が発表を行った。私は日 本建築学会の風環境数值計算 WG が 1998 年から行ってきた CFD ベンチマークテストの概要や，それに基づき 2007 年に 出版した「市街地風環境予測のための流体数值解析ガイドブ ック」を紹介した。アメリカの招待講演者の発表の中で興味 深かったのは，アメリカ海軍研究所（U.S. Naval Research Laboratory）の Gopal. Patnaik 博士の研究である。彼は危険性 ガスが都市に撒かれた直後の非定常ガス拡散予測の精度検証 を目的として，ハンブルグ大学で行われたオクラホマシティ のガス拡散実験（後述）と LES による数值計算を比較した。 LES の流入変動風は, 風洞内のスパイヤーやラフネスブロッ クを忠実に再現して計算したそうであり，実験とよく一致す る平均風速や乱流エネルギーの鉛直分布，および空間相関が 得られていた。比較の対象としていたのは，点源からパルス 的に発生させたトレーサーガス (Puff) が各測定点までに到達 する時間である。その到達時間は Puff ごとにばらつくため, 実験では 200 回, 計算では 62 回の puff が放出され, それらの 到達時間の確率密度が比較されていた。極めて大規模な LES 計算といい，流入変動風の作成方法といい, puff 到達時間の 確率密度といい, 大変興味深い発表であった。

2 日目の午後には MUST に関するセッションが行われた。 MUST とは Mock Urban Setting Test の略称であり, アメリカの 平原で行われた実測のことを指す。Photo 4 のように平原に数 多くのコンテナを並べ，ここで風速測定やガス拡散の実測が 行われた。またハンブルグ大学ではこれを対象とし, 数值解 析モデル検証用の風洞実験（Photo 5）を行っている。このセ ッションの最初の発表者は風洞実験を行った前述の Bernd Leitl 教授である。風速の測定には 2 次元の LDV を使用してお り，焦点距離 $800 \mathrm{~mm}$ と $500 \mathrm{~mm}$ の 2 種類のプローブを使い分 けているそうだ。シーディングには劇場でよく使われている Hazer のスモークジェネレーターを用いているとの由。ガス濃 度の測定には高応答 FID を使用している。実験には細心の注
意を払っており, 実験者も変えて何回も繰り返し実験を行っ て再現性をチェックしているとのことであった。実験の信頼 性は極めて高いと思われる。実験データは Excel にまとめら れていて, COST 732 のサイト http : //www. mi. uni - hamburg.de / Home.484.0.html から自由にダウンロードすることができる。

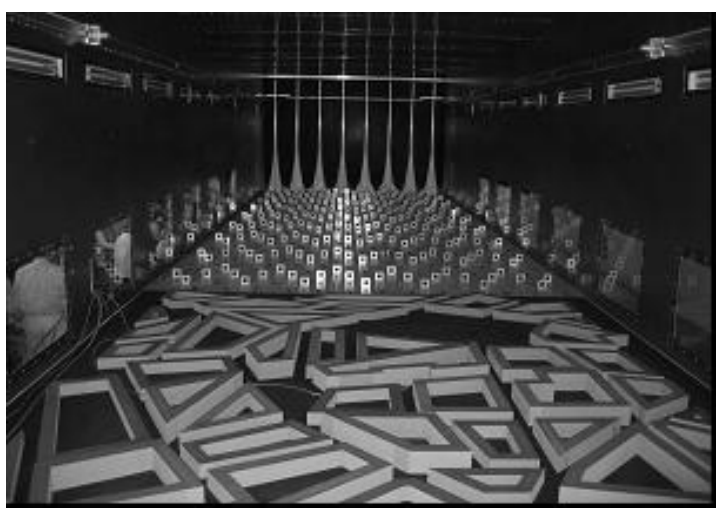

Photo 3 ハンブルグ大学の風洞内部

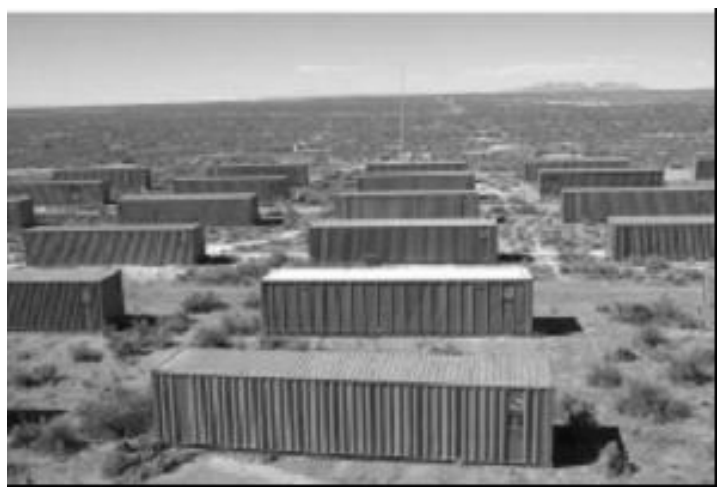

Photo 4 MUST 実測

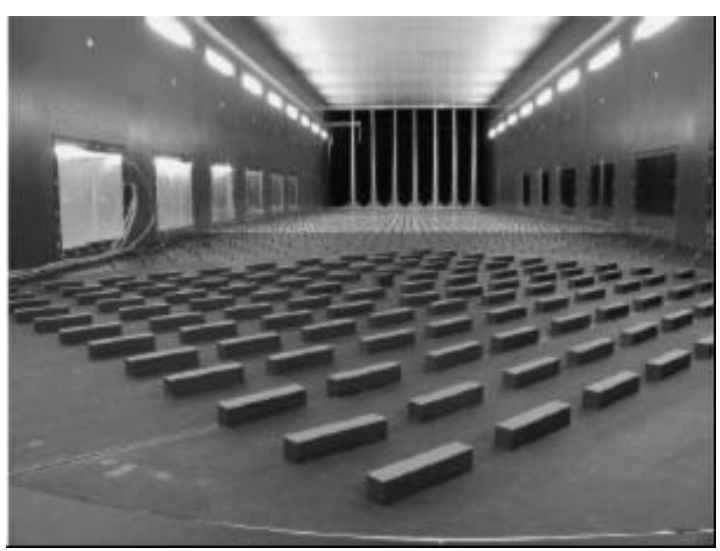

Photo 5 MUST 風洞実験 
次にイタリアUniversità del Salento の Silvana Di Sabatino准教 授らが，MUST を対象とした RANS モデルによる CFD 解析 結果と風洞実験結果との比較について発表を行った。15 の研 究グループがこのベンチマークテストに協力し，計算コード や乱流モデル等の違いを含めると延べ 40 種類の計算が行わ れたそうだ。風速の U成分は比較的よく合うが，W 成分（鉛 直成分）や乱流エネルギーはあまり合わないという報告であ った。彼らは合っているか娝かの判断指標としてヒットレイ トというものを使っている。例えばある測定点の実験值と計 算值の差が，ある許容範囲に収まっていればヒットとカウン ト寸るのである。これを全ての測定点について調べ，ヒット となった測定点の割合をヒットレイトと呼ぶのである。ドイ ツの規格 VDI では，許容範囲を $25 \%$ 以内としたヒットレイト が 0.66 以上であればよしとするらしい。他にも判断指標とし て FAC2 とか FB とか MG とかいう指標があるようで，彼ら はそれらのことを総称して Validation metrics と呼んでいた。こ れらの指標の詳細について興味のある方は, COST 732 のホ ームページから “Model Evaluation Guidance and Protocol Document”をダウンロードして読んでいただきたい。

その夜には, 湖畔のレストラン Hamburger Segel-Club (Photo 6）にて Banquet が行われた。6月のハンブルグの日は長い。 夜になっても明るい湖を眺めながら，おいしいドイツビール で喉を閏し，シーフードに舌鼓を打ったのである。会話にも 花が咲き 11 時になっても話が尽きないほどの盛り上がりで あった。

3 日目の 6 月 5 日の午前中はオクラホマシティのガス拡散 に関するセッションであった。オクラホマシティでは SF6 ガ スを充填した風船を破裂させ (Photo 7)，その後のSF6 ガスの 拡散について実測調査を行っている。ハンブルグ大学ではこ れを対象とした風洞実験も行っている（Photo 8)。昨日に引き 続き Leitl 教授が風洞実験について発表を行った。実験装置は MUST 風洞実験と同様である。平均風速分布や平均濃度分布 等を測定する実験の他に，パルス的に発生させたトレーサー ガス (Puff) が各測定点までに到達する時間を 200 回も測定し, 到達時間の確率密度を求めていた。この確率密度のデータが Patnaik 博士のLES 計算の検証に使われたのは前述のとおりで ある。次に Siegen 大学の Jörg Franke 博士が FLUENT の k $\varepsilon$ モデルを用いて計算した流れ場と濃度場を風洞実験結果と 比較した結果について発表した。Franke博士は “COST 732 Best Practice Guideline for the CFD Simulation of Flows in the Urban Environment” の筆頭執筆者である。オクラホ マシティのストリートキャニオン内の平均濃度分布の計算結 果を実験結果と比較したが，流れ場の非定常性が非常に強い ため全然合わないとのことであった。
次のセッションではパネルディスカッションが行われ，前 述のアメリカからの招待講演者やUniversity of Southampton の Ian Castro 教授等がパネラーを勤めた。私もパネラーとして前 に座らされたが，自分がしやべることを考えていて，何が議 論されたのかあまり覚えていないことは誠に面目ない。全体 を通して感じたことは, Schatzmann 教授の強力なリーダーシ

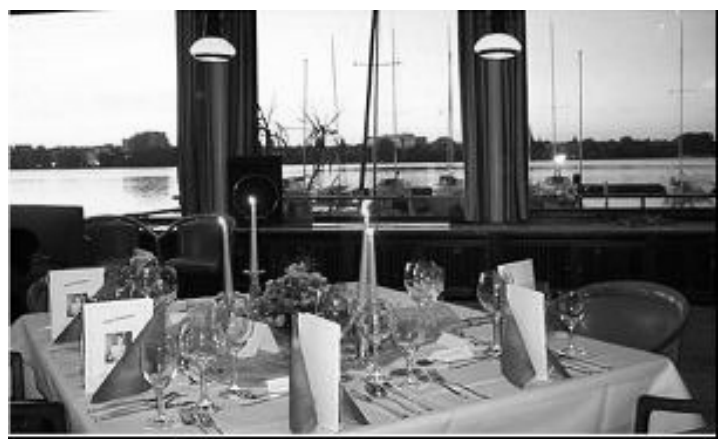

Photo 6 Hamburger Segel-Club

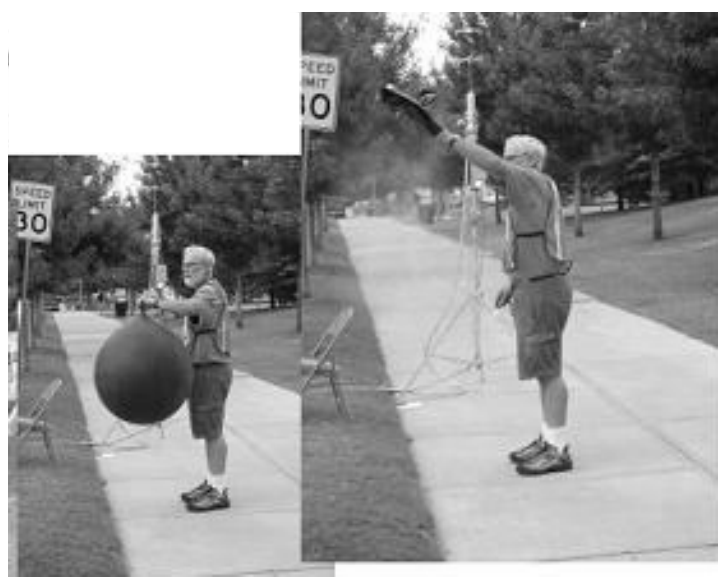

Photo 7 オクラホマシティの Puff 実測

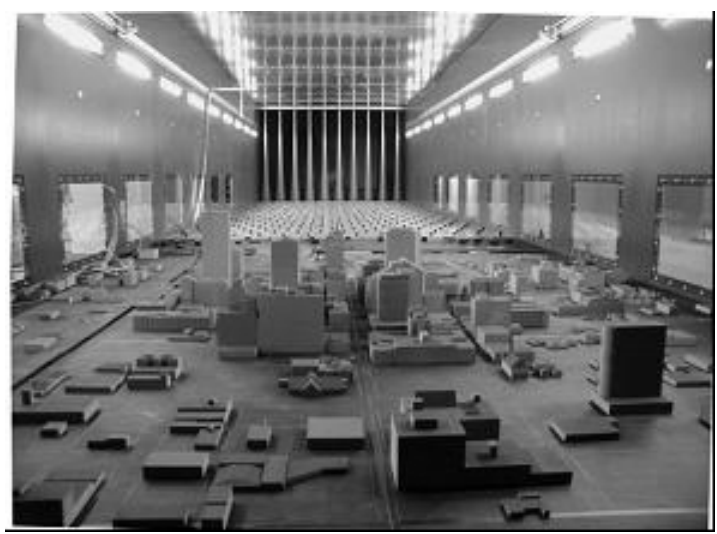

Photo 8 オクラホマシティの風洞実験 
ップの下, 数多くの研究者がこのプロジェクトに単に参加す るだけではなく, 各々が相当な労力を費やして役割を果たし ているということである。一方で年齢にかかわらず皆がお互 いをファーストネームで呼び合う家族的な䨌囲気があった。

なお, COST 732 の 4 年間の成果は以下の 5 冊の報告書にま とめられている。これらも COST 732 のサイト http : //www. mi. uni -hamburg.de/Home.484.0.html から自由にダウンロードする ことができる。

1) Proceedings, COST-ESF Workshop "Quality

Assurance of Mirco-Scale Meteorological Models", Hamburg, July 28/2, 2005.

2) COST 732 Background and Justification Document to Support the Model Evaluation Guidance and Protocol. Version May, 2007.

3) COST 732 Best Practice Guideline for the CFD Simulation of Flows in the Urban Environment. Version May 2007.

4) COST 732 Model Evaluation Guidance and Protocol Document. Version May 2007.

5) COST 732 Model Evaluation Case Studies: Approach and Results. Draft Version, May 2009.

その日の午後からは COST 内部の委員会が行われるとのこ とで，部外者の私はお役御免となった。翌朝には帰国しない といけないので，今日しかハンブルグの街を見てまわる時間 はない。夕方までハンブルグの街を懸命に俳諧した。街の景 色をいくつか示寸 (Photo 9)。夕方からはダウンタウンのビア ホールでビヤパーティーが開かれた（Photo 10）。会議が終わ った開放感もあり，昨日よりも一層会話に花が咲いたのであ る。小振りの木樽から直接注ぐドイツの地ビールは大変おい しく，酒に強くない私の体質にも合うのか，何杯飲んでも大 丈夫であった。考えてみるとハンブルグに来て以来，毎晚遅 くまでお酒を飲んでいる。この日もお開きになったのは 11 時 過ぎであった。歓楽街などを散歩してホテルに戻ったが，6 月のハンブルグは気候も大変爽やかで本当に気持ちがよい。 来る前までは，日本人ひとりで乗り込むのはいささか気が重 かったのであるが, この Workshop に参加して日本のアクティ ビティを紹介することもできたし，多くのヨーロッパやアメ リカの研究者たちと知り合い, 多くの話をすることができた。 初夏の北ドイツの雰囲気に触れることもできた。翌朝は後ろ 髪を引かれる思いで婦国の途についたのである。
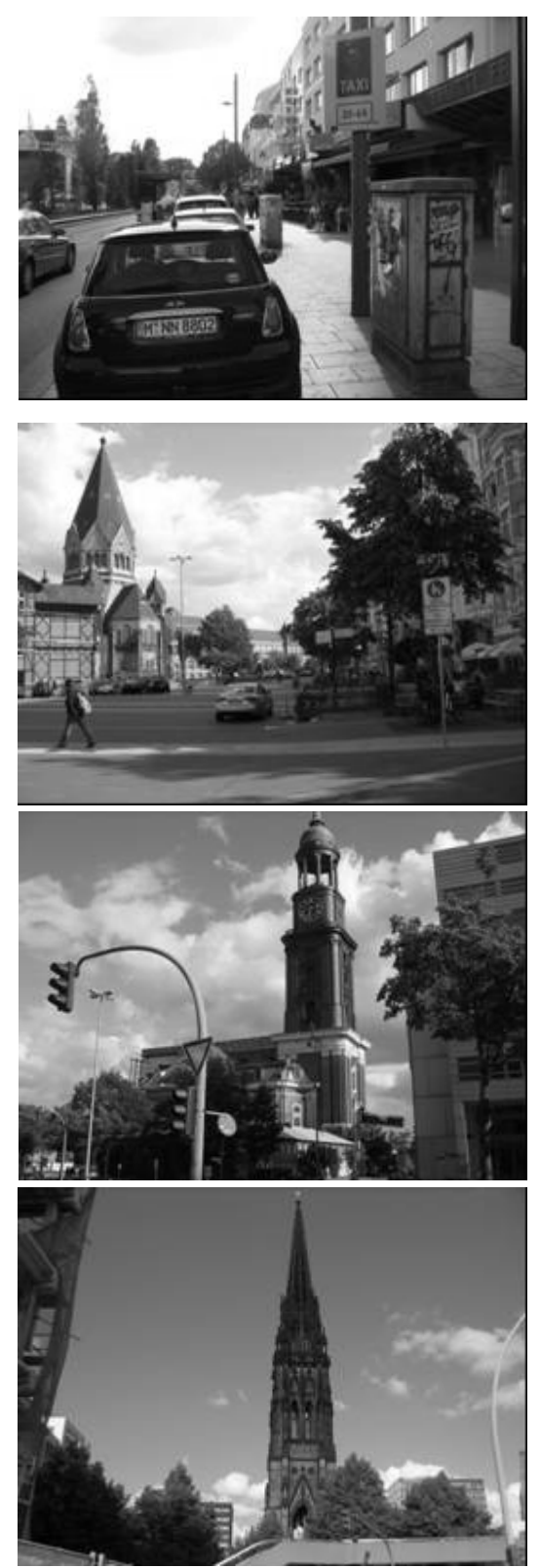

Photo 9 ハンブルグの街の風景

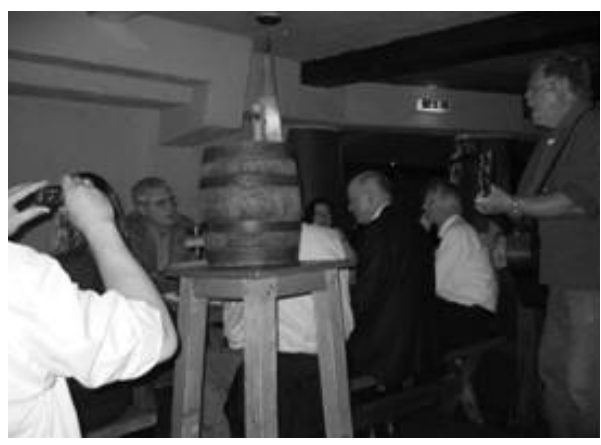

Photo 10 ビアパーティー 